\title{
Semantic Analysis of Colors and Figures Expressed in the Self-image Drawing of Students of Beauty Majors
}

\author{
Yun-Kyoung $\mathrm{Oh}^{1}$, Ae-Kyung Kim ${ }^{2 *}$ \\ ${ }^{1}$ Department of Cosmetology, Changshin University, Changwon-si, Gyeongsangnam-do, Korea \\ ${ }^{2}$ Department of Cosmetology, Tongmyong University, Busan, Korea
}

\author{
*Corresponding author: Ae-Kyung Kim, \\ Department of Cosmetology, Tongmyong \\ University, 428 Sinseon-ro, Nam-gu, Busan \\ 48520, Korea \\ Tel.: +8251629 3542 \\ Fax: +8251621 7714 \\ Email: yeskak@daum.net
}

Received May 14, 2017

Revised September 4, 2017

Accepted September 18, 2017

Published December 30, 2017

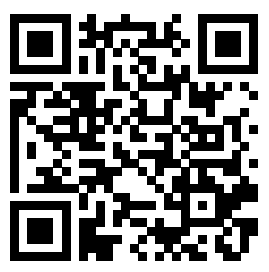

\begin{abstract}
Purpose: This study examined characteristics of colors and figures showing selfimage in self-image drawing of students of beauty majors. Methods: The researcher conducted a survey, receiving 186 completed responses. The students were made to freely draw figures showing their image with three colors. The results were analyzed by frequency analysis and cross-tab analysis, using Statistical Package for the Social Sciences (SPSS) v. 18.0. Results: First, black (Bk) was the most-used color in the self-image, followed by vivid red (R), vivid yellow (Y), vivid yellow red (YR), bright $\mathrm{Y}$, vivid purple blue $(\mathrm{PB})$, and white $(\mathrm{W})$; vivid being the most common tone. Second, from the analysis of self-image figure drawing, the results showed the use of nonobjective figures (32.3\%), landscapes (18.3\%), objects (17.2\%), people (14.5\%), plants (14.0\%), and animals (3.8\%). Third, cross-tab analysis for gender differences in selfimage drawing showed that there is a meaningful difference in chromatic colors and figures between males and females. In addition, males tend to use R, PB, YR, and Y affiliations, whereas females tend to use $Y, R$, YR, red purple (RP), and blue (B) affiliations. In figure, males have non-objective figures, landscapes, objects, and people and females have non-objective figures, objects, plants, and people. Conclusion: The self-images of students of beauty majors are expressed in colors, mainly active and attentive, and portray non-objective figures. Thus, they see themselves as having a free and enthusiastic image but are also confused and uncertain.
\end{abstract}

Keywords: Self-image, Color, Figure, Drawing, Beauty majors

\section{Introduction}

\section{1. 연구의 필요성 및 목적}

자신의 이미지를 구축하고 표현하는 것은 대인관계형성과 커뮤니케이션의 수단이 될 수 있으며, 사회적 역할이 복잡해 지고 각자의 개성이 두드러짐에 따라 개인의 정확한 이미지 를 파악하는 것이 중요하다. 일반적으로 자기이미지를 표현하 는 데는 언어가 사용되지만, 좌뇌가 지배하는 언어적 기능은 경험과 학습된 가치관으로 사실을 재해석하고 변경하기도 하 고 부인하기도 하며 종종 다른 이야기를 만들어 내기도 한다. 따라서 실제 자기이미지를 표현하기 위해서는 우뇌의 비언어 적 이미지를 사용하면 실제 자아의 있는 그대로의 상황을 얻 는데 도움이 될 것이다(quoted in Kim, 2010a; Joo \& Lee,
2015). 비언어적인 수단 중, 그림은 정서나 욕구를 전달하는 시각적 언어로서 자신의 경험, 관심, 욕구나 감정 등의 숨겨 진 내면의 세계를 표현하는 수단이 될 수 있다. 따라서 그림 에 나타난 색, 형태, 구조 등에서 개성과 사회성을 엿볼 수 있 으며, 현재에 직면한 문제를 파악할 수도 있다.

특히, 그림에 표현된 색은 인간의 감정을 표현하는 수단이 되기도 하고 정서적 반응을 일으키기도 한다. 예를 들어, 따 뜻한 색은 외향적이며, 감정이 풍부하고, 차가운 색은 내향성 과 이지적인 성향을 나타낸다(Kim, 2010b). 또한, 그림에 표 현된 형태는 그린 사람에 대한 신체적 상태와 나아가 심리적 상태까지 나타낸다. 그림의 선을 통해 목적과 방향성을 파악 할 수 있고 형태를 통해 성향과 심리상태 등을 연관 지어 볼 수 있다. 예를 들어 사각형은 고요한 휴식을 의미하는 반면, 
폐쇄적이거나 답답한 공간을 의미하기도 한다(Korean Art Psychotherapy Association, 2010).

자기이미지는 자신에 대한 생각이나 느낌을 나타내는 것으 로 개인의 생각이나 행동에 지속적인 영향을 미친다. 대학생 은 자아이미지를 확립하는 시기로 결혼 후 가정생활이나 사회 생활에 영향을 미치게 되므로 이 시기의 자기이미지를 정확하 고 깊이 있게 파악하는 것은 의미가 있을 것이다. 외적 이미 지를 가꾸는 뷰티 서비스는 개인 이미지 연출을 돕는 분야로 서, 특히 뷰티전공 대학생은 자기이미지에 대한 올바른 이해 와 확립이 필요하다. 앞서 언급한 바와 같이 비언어적 이미지 인 그림의 색과 형태는 자기이미지를 발견해 내는데 효과적임 에도 불구하고 기존의 연구에서는 주로 선호색과 관련된 경우 가 많고, 자기이미지를 대상으로 색이나 형태가 의미하는 바 를 분석한 연구는 미흡한 실정이다. 선호색은 시대, 문화, 연 령, 성별, 교육, 혈액형, 유행 등과 밀접한 연관성이 있지만 자기이미지 색은 주변의 환경보다는 자신의 심리적, 정서적인 것과 관련되고, 자신을 그대로 반영하여 성격, 외모, 취향, 가 치관 등을 드러낸다는 차이점이 있다(Sung \& Woo, 2011).

자기이미지를 그림에 표현된 색과 형태로 분석하는 것은 뷰 티전공 대학생의 자기이미지의 실제적인 표현 방법을 이해하 고 깊이 있게 파악하는데 도움을 줄 수 있을 것이다. 따라서 이 연구는 뷰티전공 대학생의 자기이미지를 시각화한 그림의 의미 분석을 통해 올바른 자기이미지 형성에 기초자료를 제공 하고자 한다.

\section{2. 이론적 배경}

1) 자기이미지

자기이미지는 self-concept 또는 self-image로 표기되며 자기개념, 자아개념, 자기이미지, 자아이미지, 자아상 등이 비슷한 개념으로 사용되고 있다. Rosenberg (1979)는 자기 이미지(self-image)를 자기 자신을 객체 혹은 하나의 대상으 로 여겨 갖게 되는 자기 자신에 대한 생각이나 느낌의 총체라 고 정의하였다. 자기이미지는 실제 자기이미지(actual selfimage)와 이상적 자기이미지(ideal self-image), 사회적 자 기이미지(social self-image), 이상적 사회적 자기이미지 (ideal social self-image)로 분류되는데 실제 자기이미지는 자신이 어떤 사람인가에 대해 개인이 가지는 이미지라고 할 수 있고 이상적 자기이미지는 개인이 바라고 추구하는 이상적 인 모습을 말한다. 사회적 자기이미지는 타인이 바라보는 자 신의 이미지를 의미하며, 이상적 사회적 자기이미지는 타인에 게 자신이 보이기 원하는 이미지를 뜻한다(Sirgy, 2015).

Kim \& Kwon (2011)은 자기이미지가 시각이미지 수용에 미치는 연관성 연구에서 20 대 여대생들의 실제적 자기이미지 는 편안하고 활동적, 쾌활한 이미지이며 이상적 자기이미지
Color pallet

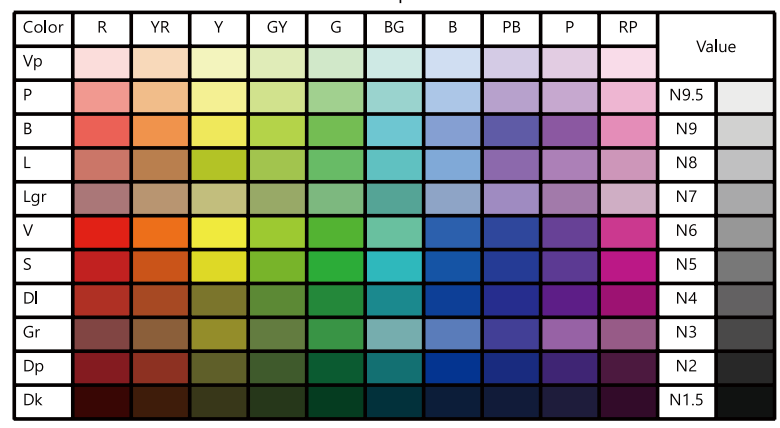

Figure 1. Color pallet.

Color pallet was produced by aligning the horizontal axis with the color and the vertical axis with the tone. R, red; $Y R$, yellow red; Y, yellow; GY, green yellow; G, green; BG, blue green; B, blue; $\mathrm{PB}$, purple blue; $\mathrm{P}$, purple; $\mathrm{RP}$, red purple; $\mathrm{Vp}$, very pale; $\mathrm{P}$, pale; B, bright; L, light; Lgr, light grayish; V, vivid; S, strong; DI, dull; Gr, grayish; Dp, deep; Dk, dark; N1.5, black, Bk; N9.5, white, W.

는 부드러우면서 세련된 이미지라고 하였는데 실제적 자기이 미지는 시각적 이미지 선호 성향에 직접적인 영향을 미친다 고 하였다. 자기이미지를 의복과 관련하여 Shim (2006)은 중 년여성을 대상으로 한 연구에서 자기이미지에 따라 의복이미 지 평가도 달라지며 선호 의복스타일에도 영향을 미친다고 하 였다. 자아개념을 연구하는데 있어서 가장 널리 이용되는 방 법은 자아보고 방법이며, 여러 가지 방법 중에서 질문지를 통 한 접근법이 가장 자주 사용되고 있다. 그러나 이러한 방법은 우리가 갖고 있는 지식이나 생각을 모두 언어적 반응으로 나 타낸다는 한계를 가진다(Goldin-Meadow, 2000). 한편, 색 은 인간의 심리적 반응을 잘 드러낼 수 있고 인간의 의식과 무의식에 영향을 미치며 감정 또는 정서에 영향을 줄 수 있어 (Arnheim, 1971), 자기이미지의 속성을 직접적으로 표현할 수 있을 것이다.

\section{2) 자기이미지 색과 형태}

Sung \& Woo (2011)는 자기이미지 색과 선호색, 모노톤 광 고 선호색 간의 상관관계 연구에서 선호색과 자기이미지 색 은 비교적 관련성이 높지만 모노톤 광고 선호색과는 일치하 지 않는다고 하였고 이는 소비자의 심리적 측면에서 특정한 색채를 언제나 선호하지는 않는다는 사실을 보여준다고 하였 다. Radeloff (1991)는 명도와 채도가 색채선호의 중요한 요 소라고 하였으며 외향적인 사람은 난색과 고명도의 색을 선호 하며, 심리적으로 기분이 우울할 때 사람들은 한색을 선호한 다고 하였다. Park (1995)은 내성적인 성격과 성취감이 강한 성격은 고명도의 색을 중명도의 색보다 더 싫어하고 공격성과 보수성을 지닌 사람들은 중명도의 색을 고명도의 색보다 더 
싫어한다고 하였고, 고명도의 색은 내성적인 사람에게 혐오감 이 높다고 하였다.

색의 연상이란 특정한 색을 보았을 때 떠올리게 되는 색채 가 가진 감성적 특성을 일컫는데, 일반적으로 빨강은 강열하 고 활동적이며, 흥분된 이미지를 연상시키고 애정이나 정열을 나타낸다. 주황은 식욕, 질투, 쾌락을 연상시키고 노랑은 환 희, 희망, 질투, 명랑을 연상시킨다. 그리고 초록은 평화와 조 화, 휴식과 생명을 연상시키는 색이고, 파랑은 젊음을 나타내 는 색으로 진리와 냉정의 이미지이다. 무채색인 하얀색은 순 결과 정직, 시작을 연상시키며 소박하고 명쾌한 이미지이다.
반면 검정은 죽음과 비애, 공포와 절망을 연상시킨다.

색과 형태의 표현과 관련하여 Alschuler \& Hattwick (1947)은 태양을 빨간색으로 그렸을 경우 정상적이고 건전한 아버지를 나타내는 반면 노란색으로 그렸을 경우 아버지에 대 한 결함을 나타낸다고 하였다. 그리고 파랑을 선과 형으로 그 릴 경우 성격이 명랑하고 주위에 잘 적응한다고 하였다. $\mathrm{Kim}$ (1998)은 빨강을 선택해서 둥글둥글한 필법으로 사용했을 경 우 애정이나 기분이 좋은 상태이며 검은색의 윤곽은 부모의 엄격한 훈육을 나타낸다고 하였다. 의상의 문양에서는 Taylor \& Compton (1968)은 작은 무늬를 선호하면 이론적인 가치관

Table 1. Distribution of color in self-image drawing

\begin{tabular}{|c|c|c|c|c|c|c|c|c|c|c|c|}
\hline $\begin{array}{l}\text { Chromatic } \\
\text { color }\end{array}$ & $\mathrm{R}$ & YR & Y & GY & G & $B G$ & B & PB & $P$ & $\mathrm{RP}$ & Total \\
\hline \multirow{3}{*}{ Pure } & $\begin{array}{c}49 \\
(8.8)\end{array}$ & $\begin{array}{c}29 \\
(5.2)\end{array}$ & $\begin{array}{c}42 \\
(7.5)\end{array}$ & $\begin{array}{c}4 \\
(0.7)\end{array}$ & $\begin{array}{c}7 \\
(1.3)\end{array}$ & $\begin{array}{c}4 \\
(0.7)\end{array}$ & $\begin{array}{c}11 \\
(2.0)\end{array}$ & $\begin{array}{c}24 \\
(4.3)\end{array}$ & $\begin{array}{c}13 \\
(2.3)\end{array}$ & $\begin{array}{c}5 \\
(0.9)\end{array}$ & $\begin{array}{c}188 \\
(33.7)\end{array}$ \\
\hline & & & & & & & & & & & \\
\hline & $\begin{array}{c}5 \\
(0.9)\end{array}$ & $\begin{array}{c}4 \\
(0.7)\end{array}$ & $\begin{array}{c}2 \\
(0.4)\end{array}$ & $\begin{array}{c}6 \\
(1.1)\end{array}$ & $\begin{array}{c}2 \\
(0.4)\end{array}$ & $\begin{array}{c}1 \\
(0.2)\end{array}$ & $\begin{array}{c}2 \\
(0.4)\end{array}$ & $\begin{array}{c}5 \\
(0.9)\end{array}$ & $\begin{array}{c}3 \\
(0.5)\end{array}$ & $\begin{array}{c}3 \\
(0.5)\end{array}$ & $\begin{array}{c}33 \\
(5.9)\end{array}$ \\
\hline \multirow{3}{*}{ Tint } & $\begin{array}{c}1 \\
(0.2)\end{array}$ & $\begin{array}{c}0 \\
(0.0)\end{array}$ & $\begin{array}{c}1 \\
(0.2)\end{array}$ & $\begin{array}{c}0 \\
(0.0)\end{array}$ & $\begin{array}{c}4 \\
(0.7)\end{array}$ & $\begin{array}{c}3 \\
(0.5)\end{array}$ & $\begin{array}{c}4 \\
(0.7)\end{array}$ & $\begin{array}{c}0 \\
(0.0)\end{array}$ & $\begin{array}{c}0 \\
(0.0)\end{array}$ & $\begin{array}{c}1 \\
(0.2)\end{array}$ & $\begin{array}{c}14 \\
(2.5)\end{array}$ \\
\hline & $\begin{array}{c}5 \\
(0.9)\end{array}$ & $\begin{array}{c}2 \\
(0.4)\end{array}$ & $\begin{array}{c}4 \\
(0.7)\end{array}$ & $\begin{array}{c}1 \\
(0.2)\end{array}$ & $\begin{array}{c}2 \\
(0.4)\end{array}$ & $\begin{array}{c}5 \\
(0.9)\end{array}$ & $\begin{array}{c}9 \\
(1.6)\end{array}$ & $\begin{array}{c}0 \\
(0.0)\end{array}$ & $\begin{array}{c}1 \\
(0.2)\end{array}$ & $\begin{array}{c}5 \\
(0.9)\end{array}$ & $\begin{array}{c}34 \\
(6.1)\end{array}$ \\
\hline & $\begin{array}{c}7 \\
(1.3)\end{array}$ & $\begin{array}{c}5 \\
(0.9)\end{array}$ & $\begin{array}{c}26 \\
(4.7)\end{array}$ & $\begin{array}{c}2 \\
(0.4)\end{array}$ & $\begin{array}{c}5 \\
(0.9)\end{array}$ & $\begin{array}{c}2 \\
(0.4)\end{array}$ & $\begin{array}{c}6 \\
(1.1)\end{array}$ & $\begin{array}{c}7 \\
(1.3)\end{array}$ & $\begin{array}{c}3 \\
(0.5)\end{array}$ & $\begin{array}{c}7 \\
(1.5)\end{array}$ & $\begin{array}{c}70 \\
(12.5)\end{array}$ \\
\hline \multirow{5}{*}{ Moderate } & $\begin{array}{c}0 \\
(0.0)\end{array}$ & $\begin{array}{c}1 \\
(0.2)\end{array}$ & $\begin{array}{c}2 \\
(0.4)\end{array}$ & $\begin{array}{c}1 \\
(0.2)\end{array}$ & $\begin{array}{c}0 \\
(0.0)\end{array}$ & $\begin{array}{c}0 \\
(0.0)\end{array}$ & $\begin{array}{c}0 \\
(0.0)\end{array}$ & $\begin{array}{c}1 \\
(0.2)\end{array}$ & $\begin{array}{c}0 \\
(0.0)\end{array}$ & $\begin{array}{c}4 \\
(0.7)\end{array}$ & $\begin{array}{c}9 \\
(1.6)\end{array}$ \\
\hline & $\begin{array}{c}3 \\
(0.5)\end{array}$ & $\begin{array}{c}1 \\
(0.2)\end{array}$ & $\begin{array}{c}2 \\
(0.4)\end{array}$ & $\begin{array}{c}0 \\
(0.0)\end{array}$ & $\begin{array}{c}0 \\
(0.0)\end{array}$ & $\begin{array}{c}1 \\
(0.2)\end{array}$ & $\begin{array}{c}7 \\
(1.3)\end{array}$ & $\begin{array}{c}1 \\
(0.2)\end{array}$ & $\begin{array}{c}0 \\
(0.0)\end{array}$ & $\begin{array}{c}0 \\
(0.0)\end{array}$ & $\begin{array}{c}15 \\
(2.7)\end{array}$ \\
\hline & & & & & & & & & & & \\
\hline & $\begin{array}{c}1 \\
(0.2)\end{array}$ & $\begin{array}{c}13 \\
(2.3)\end{array}$ & $\begin{array}{c}1 \\
(0.2)\end{array}$ & $\begin{array}{c}0 \\
(0.0)\end{array}$ & $\begin{array}{c}3 \\
(0.5)\end{array}$ & $\begin{array}{c}6 \\
(1.1)\end{array}$ & $\begin{array}{c}2 \\
(0.4)\end{array}$ & $\begin{array}{c}1 \\
(0.2)\end{array}$ & $\begin{array}{c}7 \\
(1.3)\end{array}$ & $\begin{array}{c}5 \\
(0.9)\end{array}$ & $\begin{array}{c}39 \\
(7.0)\end{array}$ \\
\hline & $\begin{array}{c}1 \\
(0.2)\end{array}$ & $\begin{array}{c}2 \\
(0.4)\end{array}$ & $\begin{array}{c}0 \\
(0.0)\end{array}$ & $\begin{array}{c}2 \\
(0.2)\end{array}$ & $\begin{array}{c}0 \\
(0.0)\end{array}$ & $\begin{array}{c}0 \\
(0.0)\end{array}$ & $\begin{array}{c}0 \\
(0.0)\end{array}$ & $\begin{array}{c}0 \\
(0.0)\end{array}$ & $\begin{array}{c}1 \\
(0.2)\end{array}$ & $\begin{array}{c}0 \\
(0.0)\end{array}$ & $\begin{array}{c}6 \\
(1.1)\end{array}$ \\
\hline \multirow[b]{2}{*}{ Shade } & $\begin{array}{c}2 \\
(0.4)\end{array}$ & $\begin{array}{c}7 \\
(1.3)\end{array}$ & $\begin{array}{c}0 \\
(0.0)\end{array}$ & $\begin{array}{c}2 \\
(0.4)\end{array}$ & $\begin{array}{c}2 \\
(0.4)\end{array}$ & $\begin{array}{c}3 \\
(0.5)\end{array}$ & $\begin{array}{c}1 \\
(0.2)\end{array}$ & $\begin{array}{c}8 \\
(1.4)\end{array}$ & $\begin{array}{c}6 \\
(1.1)\end{array}$ & $\begin{array}{c}6 \\
(1.1)\end{array}$ & $\begin{array}{c}37 \\
(6.6)\end{array}$ \\
\hline & $\begin{array}{c}1 \\
(0.2)\end{array}$ & $\begin{array}{c}1 \\
(0.2)\end{array}$ & $\begin{array}{c}0 \\
(0.0)\end{array}$ & $\begin{array}{c}0 \\
(0.0)\end{array}$ & $\begin{array}{c}0 \\
(0.0)\end{array}$ & $\begin{array}{c}0 \\
(0.0)\end{array}$ & $\begin{array}{c}0 \\
(0.0)\end{array}$ & $\begin{array}{c}5 \\
(0.9)\end{array}$ & $\begin{array}{c}1 \\
(0.2)\end{array}$ & $\begin{array}{c}3 \\
(0.5)\end{array}$ & $\begin{array}{c}11 \\
(2.0)\end{array}$ \\
\hline Total & $\begin{array}{c}75 \\
(13.4)\end{array}$ & $\begin{array}{c}65 \\
(11.6)\end{array}$ & $\begin{array}{c}80 \\
(14.3)\end{array}$ & $\begin{array}{c}18 \\
(3.2)\end{array}$ & $\begin{array}{c}25 \\
(4.5)\end{array}$ & $\begin{array}{c}25 \\
(4.5)\end{array}$ & $\begin{array}{c}42 \\
(7.5)\end{array}$ & $\begin{array}{c}52 \\
(9.4)\end{array}$ & $\begin{array}{c}35 \\
(6.3)\end{array}$ & $\begin{array}{c}39 \\
(7.0)\end{array}$ & $\begin{array}{c}456 \\
(81.7)\end{array}$ \\
\hline \multirow{3}{*}{ Achromatic color } & \multicolumn{4}{|c|}{ Low-brightness } & \multicolumn{3}{|c|}{ Middle-brightness } & \multicolumn{3}{|c|}{ High-brightness } & Total \\
\hline & N1.5 & N2 & N3 & N4 & N5 & N6 & N7 & N8 & N9 & N9.5 & Iotal \\
\hline & $\begin{array}{c}66 \\
(11.8)\end{array}$ & $\begin{array}{c}0 \\
(0.0)\end{array}$ & $\begin{array}{c}0 \\
(0.0)\end{array}$ & $\begin{array}{c}3 \\
(0.5)\end{array}$ & $\begin{array}{c}2 \\
(0.4)\end{array}$ & $\begin{array}{c}3 \\
(0.5)\end{array}$ & $\begin{array}{c}4 \\
(0.7)\end{array}$ & $\begin{array}{c}5 \\
(0.9)\end{array}$ & $\begin{array}{c}0 \\
(0.0)\end{array}$ & $\begin{array}{c}19 \\
(3.5)\end{array}$ & $\begin{array}{c}102 \\
(18.3)\end{array}$ \\
\hline
\end{tabular}

R, red; YR, yellow red; Y, yellow; GY, green yellow; G, green; BG, blue green; B, blue; PB, purple blue; P, purple; RP, red purple; V, vivid; S, strong; Vp, very pale; P, pale; B, bright; L, light; Lgr, light grayish; DI, dull; Gr, grayish; Dp, deep; Dk, dark; N1.5, black, Bk; N9.5, white, W. 
이 높고, 큰 무늬를 선호하면 심미적인 가치관이 높다고 하였 으며, Kim \& Lee (1992)는 사실무늬는 성취성이 강할수록, 기하학적인 무늬와 추상적인 무늬는 다양성이 높을수록 선호 한다고 하였다. 또한, Lee \& $\operatorname{Kim}$ (1997)은 자신이 남성적으 로 지각되기를 원하면 세로줄 무늬를 선호하고, 여성적으로 지각되기를 원하면, 화려한 무늬를 선호한다고 하였다.

\section{Methods}

부산 및 경상남도 지역의 뷰티전공 남녀 대학생 200명을 대상으로, 2016년 6월 1일에서 6월 21일에 걸쳐 자기이미지 그림 자료를 수집하였다. 수집된 자료 중 부적합한 것을 제 외한 186명(남, 81명; 여, 105 명)의 자료를 최종 분석에 사 용하였다. 형태는 대상자에게 자신의 이미지를 연상해서, 테
두리가 그려진 A4 용지에 $20 \mathrm{~min}$ 동안 자유롭게 그리도록 하였다. 그리고 자신의 이미지를 연상시키는 색은 120 색으 로 제작한 색 파렛트(Figure 1)를 제시하여, 이 중 색채 심 리 검사법(Kim \& Je, 2013)을 참고하여 3가지 색을 선택하 도록 하였다. 색지는 먼셀의 색체계를 바탕으로 제작된 J사 의 제품으로, 본문에서는 red (R), yellow red (YR), yellow $(\mathrm{Y})$, green yellow $(\mathrm{GY})$, green $(\mathrm{G})$, blue green $(\mathrm{BG})$, blue (B), purple blue (PB), purple (P), red purple (RP), black $(\mathrm{Bk})$, white $(\mathrm{W})$ 의 색은 약자로 표기하였다. Tone의 표기 는 very pale $(\mathrm{Vp})$, pale $(\mathrm{P})$, bright $(\mathrm{B})$, light (L), light grayish (Lgr), vivid (V), strong (S), dull (Dl), grayish $(\mathrm{Gr})$, deep (Dp), dark (Dk)로 표기하면서, 11단계의 유사한 색조를 정리하여 pure $(\mathrm{V}, \mathrm{S})$, tint $(\mathrm{Vp}, \mathrm{P}, \mathrm{B})$, moderate $(\mathrm{L}, \mathrm{Lgr}, \mathrm{Dl}, \mathrm{Gr})$, shade $(\mathrm{Dp}, \mathrm{Dk})$ 의 4 단계로 구분하였다. 무채색은 N1.5 (Bk)에서 N9.5 (W)까지 10단계의 영역으로

Table 2. Figure expressed in the self-image

\begin{tabular}{|c|c|c|c|}
\hline Figure & & Number (\%) & Contents \\
\hline \multirow{4}{*}{ Plant } & Tree & $12(46.1)$ & \multirow{4}{*}{ Detailed petals, flower bouquet, lush leaf, reed, stem, etc. } \\
\hline & Flower & $11(42.3)$ & \\
\hline & Fruit & $3(11.5)$ & \\
\hline & Total & $26(14.0)$ & \\
\hline \multirow{7}{*}{ Landscape } & Mountain and sea & $9(26.4)$ & \multirow{7}{*}{$\begin{array}{l}\text { Natural landscape, complex and concrete expression, } \\
\text { apartment, house, etc. }\end{array}$} \\
\hline & Mountain & $8(23.5)$ & \\
\hline & Sea & $7(20.5)$ & \\
\hline & Building & $6(17.6)$ & \\
\hline & Sky & $3(8.8)$ & \\
\hline & Road & $1(2.9)$ & \\
\hline & Total & $34(18.3)$ & \\
\hline \multirow{4}{*}{ Animal } & Big animal & $3(42.8)$ & \multirow{4}{*}{ Giraffe, elephant, rabbit, cat, butterfly, etc., abbreviated form } \\
\hline & Small animal & $3(42.8)$ & \\
\hline & Insect & $1(14.2)$ & \\
\hline & Total & $7(3.8)$ & \\
\hline \multirow{5}{*}{ People } & Whole body & $11(40.7)$ & \multirow{5}{*}{ Specific body, facial expression, emoticon } \\
\hline & Face & $9(33.3)$ & \\
\hline & Parts of the body & $5(18.5)$ & \\
\hline & Character & $2(7.4)$ & \\
\hline & Total & $27(14.5)$ & \\
\hline \multirow{4}{*}{ Object } & Fashion goods & $16(50.0)$ & \multirow{4}{*}{$\begin{array}{l}\text { Clothes, bag, accessories, figures, guitar, fire flames, lipstick, } \\
\text { dresser set, shoes, watch, balloon, etc. }\end{array}$} \\
\hline & Household goods & $13(40.6)$ & \\
\hline & Etc. & $3(9.3)$ & \\
\hline & Total & $32(17.2)$ & \\
\hline \multirow{3}{*}{ Non-objectivity } & Abstract & $38(63.3)$ & \multirow{3}{*}{ Complex lines and faces, simple geometric shapes } \\
\hline & Figure & $22(36.6)$ & \\
\hline & Total & $60(32.3)$ & \\
\hline
\end{tabular}


A

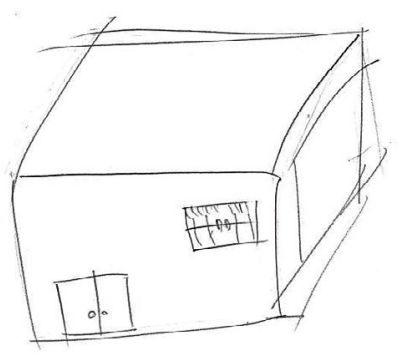

B

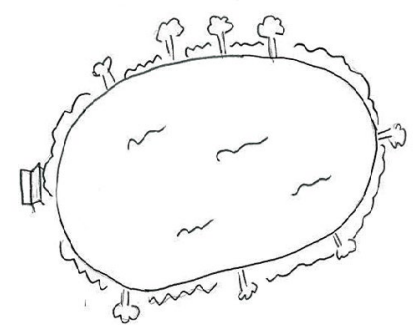

C

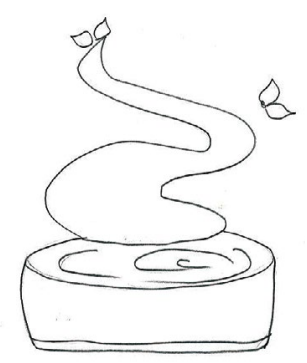

Figure 2. Case of figures.

A building $(A)$, a natural landscape $(B)$, and a tree $(C)$ are examples of self-image expressions.

제시하였고 10 단계의 유사한 단계를 정리하여 저명도(lowbrightness; N1.5-4), 중명도(middle-brightness; N5N7), 고명도(high-brightness; N8-9.5)의 3단계로 하였다.

이 연구는 SPSS 18.0 프로그램(IBM, USA)을 활용하여 통 계분석과 내용분석을 실시하였다.

자기이미지 색과 형태 분석은 빈도분석을 사용하였고, 자 기이미지 색의 성별차이는 교차분석을 실시하였다. 자기이미 지 그림에 나타난 색과 형태를 분석하기 위해 다음과 같은 연 구문제를 설정하였다.

연구문제 1. 뷰티전공 대학생의 자기이미지 그림에 나타난 색을 분석한다.
연구문제 2. 뷰티전공 대학생의 자기이미지 그림에 나타난 형태를 분석한다.

연구문제 3. 성별에 따른 뷰티전공 대학생의 자기이미지 그 림에 나타난 색과 형태의 차이를 알아본다.

\section{Results and Discussion}

\section{1. 자기이미지 그림에 나타난 색의 분석}

뷰티전공 대학생의 그림에 나타난 자기이미지의 색을 분석 하기 위해 빈도분석을 실시하였으며, 그 결과는 Table 1과 같 다. 자기이미지 색으로 가장 많이 나타난 색은 Bk (N1.5)이었 으며 다음으로 vivid R, vivid $\mathrm{Y}$, vivid $\mathrm{YR}$, bright $\mathrm{Y}$, vivid $\mathrm{PB}, \mathrm{W}$ (N9.5) 순이었다. 무채색이 전체의 $18.3 \%$ 이고, 유 채색에서는 $\mathrm{Y}$ 계열과 $\mathrm{R}$ 계열, $\mathrm{YR}$ 계열이 전체의 각각 $14.3 \%$, $13.4 \%, 11.6 \%$ 이었으며, 마지막으로PB계열이 $9.4 \%$ 로 나타났 다. Tone은 vivid가 전체의 $33.7 \%$ 로 가장 많으며, 그 다음으 로 bright가 $12.5 \%$, dull과 deep이 각각 $7.0 \%, 6.6 \%$ 로 나타 났다. $\mathrm{Bk}$ 를 제외하면 따뜻한 색 위주로 선택하고 있음을 알 수 있다. 선행연구와 비교하면, Sung \& Woo (2011)의 연구 에서는 $\mathrm{B}, \mathrm{Bk}, \mathrm{R}$ 순으로 나타나 이 연구의 결과와는 일치하 지 않는데, 해당 연구는 10 대에서 40 대까지를 연구대상으로 한 것이기에 이 연구와 다소 차이가 나타난 것으로 사료된다.

뷰티전공 대학생이 자신을 나타내는 색을 vivid R, vivid $\mathrm{Y}$, vivid $\mathrm{YR}$ 과 $\mathrm{Bk}$ 등으로 드러내고 있는 것은 R과 $\mathrm{YR}$ 은 강렬 하고, 정열적이고, 젊음을 상징하는 색으로 젊음의 특징인 활 기차고 미래지향적이고 외향적인 특성을 나타낸다고 볼 수 있 으며, 반면에 충동적이고 본능이 강한 20 대 대학생의 특징을 반영하고 있음을 알 수 있다. 또한, $\mathrm{Bk}$ 는 부정적인 이미지로 어둠과 죽음, 우울의 의미가 강하지만 새로운 발생의 약속으 로 대학생의 특성과 닮아있음을 알 수 있다. 이와 같은 결과 는 정열적이지만 사회에 비판적인 사고와 미래에 대한 불안감 이 공존하는 등 아직 미성숙한 자아를 감추기 위한 현대의 대 학생의 특성을 설명할 수 있는 것으로 생각된다.

\section{2. 자기이미지 그림에 나타난 형태의 분석}

자기이미지를 연상하여 자유롭게 표현한 그림을 빈도분석 과 내용분석으로 알아본 결과는 Table 2 와 같고 그림의 예시 는 Figure 2 와 같다. 자기이미지로 표현된 형태는 크게 식물, 풍경, 동물, 사람, 사물, 비구상으로 분류하여 분석하였다. 결 과를 살펴보면, 비구상이 $32.3 \%$ 로 가장 많았고, 그 다음으로 풍경(18.3\%), 사물(17.2\%), 사람(14.5\%), 식물(14.0\%)과 동 물 $(3.8 \%)$ 순이었다.

식물은 주로 나무(46.1\%)와 꽃(42.3\%)으로 표현하였는데 
나무는 대부분 한 그루를 전체적으로 표현하였으며 잎과 꽃이 풍성하게 피어있는 경우가 많았다. 드물게 갈대나 앙상한 가 지 형태를 표현하기도 하였다. 꽃은 대부분 꽃잎을 위주로 그 리거나 줄기와 잎을 함께 그리기도 하였다. 간혹 꽃다발이나 생략화 형태로 나타낸 경우도 있었다. 과일은 둥근 형으로 표 현하였으며 구체적인 형태를 나타냈다. 풍경 중에서는 산과 바다(26.4\%)를 함께 표현하거나 산(23.5\%), 바다(20.5\%)를 따로 표현하는 경우가 많았으며 건물(17.6\%)을 표현한 경우 도 있었다. 건물은 주택이나 아파트 형태로 표현하였고 주변 풍경을 같이 그린 경우가 많았다.

동물은 기린, 코끼리 등 큰 동물 $(42.8 \%)$ 을 표현하거나 고양이, 토끼 등 작은 동물(42.8\%)을 표현하였으며 곤충 (14.2\%)을 표현한 경우도 있었다. 동물을 그린 경우는 구체적 으로 그리기보다는 대략적인 형태를 그린 경우가 많았다. 사 람을 자기이미지로 표현한 경우는 전신(40.7\%)을 그리거나 얼굴(33.3\%) 또는 눈, 입과 같은 신체 일부(18.5\%)를 그렸으
며 얼굴은 표정을 나타낸 경우가 많았다. 이모티콘 등(7.4\%) 을 사용하여 간략하게 그리기도 하였다.

사물은 옷과 액세서리 같은 패션용품 $(50.0 \%)$ 과 립스틱, 시 계, 풍선과 같은 생활용품(40.6\%)을 나타낸 경우가 많았다. 비구상은 추상 $(63.3 \%)$ 과 도형(36.6\%)으로 표현하였으며 추 상을 표현한 경우는 선을 복잡하게 표현한 경우가 많았으며 도형은 사각형이나 동그라미와 같이 간단하게 나타낸 경우가 많았다.

\section{3. 자기이미지 그림에 나타난 색과 형태의 성별차이}

1) 성별에 따른 자기이미지 색 차이

자신의 이미지로 선택한 색의 성별차이를 분석하기 위해 교 차분석을 사용하였으며, 그 결과는 Table 3 과 같다. 자기이 미지 색을 색상(유채색), 무채색, 톤으로 구분하여 비교한 결 과 색상(유채색)에서 유의한 차이가 나타났다. 남학생은 R계 열(19.3\%)을 선택한 경우가 가장 많고, 그 다음으로 PB계열

Table 3. Self-image color according to gender

\begin{tabular}{|c|c|c|c|c|}
\hline \multicolumn{2}{|c|}{ Gender } & \multicolumn{2}{|c|}{ Number (Gender \%) } & \multirow{2}{*}{ Total } \\
\hline Color & & Male & Female & \\
\hline \multirow{12}{*}{ Chromatic color } & $\mathrm{R}$ & $37(19.3)$ & $41(15.5)$ & $78(17.1)$ \\
\hline & YR & $26(13.5)$ & 39 (14.8) & $65(14.3)$ \\
\hline & Y & $23(12.0)$ & $57(21.6)$ & $80(17.5)$ \\
\hline & GY & $6(3.1)$ & $12(4.5)$ & $18(3.9)$ \\
\hline & G & $14(7.3)$ & $11(4.2)$ & $25(5.5)$ \\
\hline & $B G$ & $12(6.3)$ & $10(3.8)$ & $22(4.8)$ \\
\hline & $\mathrm{B}$ & $16(8.3)$ & $26(9.8)$ & $42(9.2)$ \\
\hline & PB & $33(17.2)$ & $19(7.2)$ & $52(11.4)$ \\
\hline & $\mathrm{P}$ & $13(6.8)$ & $22(8.3)$ & $35(7.7)$ \\
\hline & RP & $12(6.3)$ & $27(10.2)$ & $39(8.6)$ \\
\hline & Total & $192(100.0)$ & $264(100.0)$ & $456(100.0)$ \\
\hline & $x^{2}(p)$ & \multicolumn{2}{|c|}{$23.242(0.006)$} & \\
\hline \multirow{5}{*}{ Achromatic color } & Low-brightness & $35(68.6)$ & $34(66.7)$ & $69(67.6)$ \\
\hline & Middle-brightness & $4(7.8)$ & $5(9.8)$ & $9(8.8)$ \\
\hline & High-brightness & $12(23.5)$ & $12(23.5)$ & $24(23.5)$ \\
\hline & Total & $51(100.0)$ & $51(100.0)$ & $102(100.0)$ \\
\hline & $x^{2}(p)$ & \multicolumn{2}{|c|}{$0.126(0.939)$} & \\
\hline \multirow{6}{*}{ Tone } & Pure & $86(44.8)$ & $140(53.0)$ & $226(49.6)$ \\
\hline & Tint & $47(24.5)$ & $67(25.4)$ & $114(25.0)$ \\
\hline & Moderate & $36(18.8)$ & $33(12.5)$ & $69(151.1)$ \\
\hline & Shade & $23(12.0)$ & $24(9.1)$ & $47(10.3)$ \\
\hline & Total & $192(100.0)$ & $264(100.0)$ & $456(100.0)$ \\
\hline & $x^{2}(p)$ & \multicolumn{2}{|c|}{$5.328(0.149)$} & \\
\hline
\end{tabular}

R, red; YR, yellow red; Y, yellow; GY, green yellow; G, green; BG, blue green; B, blue; PB, purple blue; P, purple; RP, red purple. $x^{2}(p)=$ Chi-square test ( $p$-value). 
(17.2\%), YR계열(13.5\%), Y계열(12.0\%) 순으로 나타났으 며, 여학생은 Y계열 $(21.6 \%)$ 이 가장 많고, 그 다음으로 R계열 (15.5\%), YR계열(14.8\%), RP계열(10.2\%), B계열(9.8\%) 순 으로 나타났다. 무채색을 선택한 경우 남녀 모두 저명도를 가 장 많이 선택하였으며 중명도를 가장 적게 선택하였다. 톤은 pure tone을 가장 많이 선택하였고 shade tone을 가장 적게 선택하였다. 이상의 결과에서, 자기이미지를 나타내는 색은 남녀의 차이가 뚜렷함을 알 수 있다. 남학생은 R계열, $\mathrm{PB}$ 계 열, $\mathrm{G}$ 계열에서 여학생보다 비율이 높으며, 여학생은 Y계열, $\mathrm{YR}$ 계열, $\mathrm{RP}$ 계열의 색상에서 남학생보다 높은 비율을 나타내 고 있다. 그래서 여학생은 주로 난색을, 남학생은 난색, 한색, 중성색을 자신의 이미지 색으로 표출하고 있음을 알 수 있다.

\section{2) 성별에 따른 자기이미지의 형태 차이}

자기이미지로 표현된 형태의 성별차이를 분석하기 위해 교 차분석을 사용하였으며, 그 결과는 Table 4 와 같다. 분석결 과 자기이미지 형태에 대하여 남녀의 차이가 유의한 것으로 나타났다. 남학생은 비구상(39.5\%)이 가장 많고, 그 다음으 로 풍경(22.2\%), 사물(13.6\%), 사람(12.3\%) 순으로 나타났 고, 여학생은 비구상(26.7\%)이 가장 많고, 그 다음으로 사물 (20.0\%), 식물(17.1\%), 사람(16.2\%) 순으로 나타났다. 남녀 모두 비구상의 표현으로 자아이미지를 가장 많이 그렸으며 그 다음으로는 남학생은 풍경을, 여학생은 사물을 표현하고 있 어, 남학생은 전체를 보는 관점이라면, 여학생은 부분과 디테 일 표현으로 자신을 보는 차이가 있음을 알 수 있다. 또한, 남 학생은 비구상, 풍경에서 여학생보다 비율이 높으며, 여학생 은 사물, 식물, 사람, 동물에서 남학생보다 나타나는 비율이 높아 남학생보다 여학생이 자신의 이미지를 다양하게 표현하 고 있음을 알 수 있다.

\section{Conclusion}

이 연구는 남녀 186 명의 뷰티전공 대학생을 대상으로 자기 이미지를 자유롭게 표현하도록 하고 자신을 나타내는 색을 선 택하도록 하였다. 그림에 나타난 색과 형태를 분석한 결과는 다음과 같다.

첫째, 자기이미지의 색을 분석한 결과, $\mathrm{Bk}$ 가 가장 많고 다 음으로 vivid R, vivid $\mathrm{Y}$, vivid $\mathrm{YR}$, bright $\mathrm{Y}$, vivid $\mathrm{PB}, \mathrm{W}$ 순이며, tone은 vivid가 가장 많이 나타났다. 둘째, 자기이미 지 그림에 나타난 형태를 분석한 결과, 비구상, 풍경, 사물, 사람, 식물, 동물 순으로 자신의 이미지를 다양한 형태로 표 현하였다. 셋째, 자기이미지에 나타난 성별 차이를 분석한 결 과, 유채색과 형태에서 유의한 차이가 나타났는데 색지의 선 택에서 남학생은 R계열, $\mathrm{PB}$ 계열, $\mathrm{YR}$ 계열, $\mathrm{Y}$ 계열 순으로, 여 학생은 $\mathrm{Y}$ 계열, R계열, $\mathrm{YR}$ 계열, RP계열, $\mathrm{B}$ 계열 순으로 선택 하였으며, 형태에서 남학생은 비구상, 풍경, 사물, 사람 순으 로, 여학생은 비구상, 사물, 식물, 사람 순으로 표현하였다.

이상의 결과에서 뷰티전공 대학생은 자기이미지 색으로 $\mathrm{Bk}$ 와 vivid R, vivid $\mathrm{Y}$ 등 활동성과 주목성이 강한 색으로 표현 하고, 형태는 정형화된 모양이나 사물보다는 비구상적인 것으 로 많이 표현하며, 남학생은 전체를, 여학생은 부분적인 것으 로 자신을 투영하는 것을 알 수 있었다. 이는 대학생이 자신 을 자유롭고 열정적인 이미지로 생각하기도 하는 반면 혼란스 럽고 불확실하게 그려내기도 한다는 것을 의미한다. 또한 남 녀의 차이가 분명하여 이에 따른 주의가 필요함을 알 수 있 다.

자기이미지 색이 $\mathrm{Bk}$ 가 가장 많은 것은 시사하는 바가 큰 것 으로 사료된다. $\mathrm{Bk}$ 색상에 어둠과 죽음, 우울의 의미가(Kim $\& \mathrm{Je}, 2013)$ 담겨있으므로 이러한 선택이 뷰티전공 대학생의 정신건강 측면에서 관련성이 있는지 더 연구해볼 필요가 있을 것이다.

Table 4. Self-image figure according to gender

\begin{tabular}{lrrr} 
& \multicolumn{2}{c}{ Number (Gender \%) } & Total \\
\hline Figure & Male & Female & $26(14.0)$ \\
Plant & $8(9.9)$ & $18(17.1)$ & $34(18.3)$ \\
Landscape & $18(22.2)$ & $16(15.2)$ & $7(3.8)$ \\
Animal & $2(2.5)$ & $5(4.8)$ & $27(14.5)$ \\
People & $10(12.3)$ & $17(16.2)$ & $32(17.2)$ \\
Object & $11(13.6)$ & $21(20.0)$ & $60(32.3)$ \\
Non-objectivity & $32(39.5)$ & $28(26.7)$ & $186(100.0)$ \\
Total & $81(100.0)$ & $105(100.0)$ & $22.451(0.000)$ \\
$X^{2}(p)$ & & & \\
\hline
\end{tabular}

$x^{2}(p)=$ Chi-square test $(p$-value). 
이 연구는 뷰티전공 대학생에 대하여 한정적으로 이루어졌 으므로 확대해석에는 주의가 필요하며 향후 다른 지역이나 타 전공으로 확대하여 비교해 보거나 대상자의 성격, 생활환경에 따른 차이를 연구해 볼 수 있을 것이다.

\section{References}

Alschuler RH, Hattwick LB. Painting and personality: a study of young children. University of Chicago Press, Chicago, pp20-25, 1947.

Arnheim R. Art and visual perception: a psychology of the creative eye. University of California Press, Oakland, p207, 1971.

Goldin-Meadow S. Beyond words: the importance of gesture to researchers and learners. Child Development, 71: 231-239, 2000.

Joo YJ, Lee SH. The effects of the life style for Korean middle aged women on pursued self-images of make up and the purchase pattern for cosmetics. Asian Journal of Beauty and Cosmetology, 13: 533-542, 2015.

Kim AK, Je GY. Beauty color. Gyomoon Publishers, Paju, pp107-113, 2013.

Kim EA, Lee M. Clothing image and clothing design preferences relating to personal values. Journal of the Korean Society of Costume, 18: 269-281, 1992.

Kim HJ. Color psychology. Dongguk Publishing, Paju, p159, 2010a. (Birren F. 1950.)

Kim JE. Psychological diagnosis of children by picture. Kyoyookbook, Paju, pp103-105, 1998.

Kim MK. Color therapy. Haklim, Seoul, p29, $2010 b$.

Kim S, Kwon H. Research on interrelationship between self-image and receptivity of visual image: focusing on female students in their 20's. Journal of Basic Design \& Art, 12: 99-112, 2011.

Korean Art Psychotherapy Association. Reading the mind with pictures: second story. Korean Art Psychotherapy Association, Busan, p113, 2010.

Lee $\mathrm{MH}$, Kim HJ. A study on image preferences of clothing styles and self-image. Journal of the Korean Society of Costume, 33: 41-53, 1997.

Park HS. Color preferences according to personality types in term of color attributes. Journal of the Korean Society of Costume, 26: 87-100, 1995.

Radeloff DJ. Psychological types, color attributes, and color preferences of clothing, textiles, and design students. Clothing and Textiles Research Journal, 9: 59-67, 1991.

Rosenberg M. Conceiving the self. Basic Books, New York, pp292-293, 1979.

Shim JH. A study on clothing image evaluation and preference according to self-image classification of the middle-aged women. Journal of the Korean Society of Clothing and Textiles, 30: 1608-1617, 2006.

Sirgy MJ. Self-image/product-image congruity and advertising strategy. In: Proceedings of the 1982 academy of marketing science (AMS) annual conference. Kothari V, Arnold DR, Cavusgil T, Lindquist JD, Nathan J, Reid S (eds.), Springer Science+Business Media, Berlin, pp129-133, 2015.

Sung K, Woo Y. A study on the correlation between preference on colors, self image colors, monotone advertising colors. Journal of Communication Design, 35: 182-190, 2011.

Taylor LC, Compton NH. Personality correlates of dress conformity. Journal of Home Economics, 60: 653-656, 1968. 


\section{국문초록}

\section{뷰티전공 대학생의 자기이미지로 표현된 색과 형태의 의미 분석}

오윤경 ${ }^{1}$, 김애경 ${ }^{2 *}$

${ }^{1}$ 창신대학교 미용예술학과, 경상남도 창원시, 한국

${ }^{2}$ 동명대학교 뷰티케어학과, 부산, 한국

목적: 자기이미지를 색과 형태로 나타내도록 하여 뷰티전공 대학생의 자기이미지를 시각화한 그림의 의미를 분석하고자 한다. 방 법: 뷰티전공 남녀 대학생을 대상으로 자신의 이미지를 연상해서 형태를 자유롭게 그리게 하고, 120 색으로 제작한 색 파렛트를 제 시하여 이 중 자신의 이미지에 부합되는 3가지 색을 선택하도록 하였다. 결과분석은 Statistical Package for the Social Sciences (SPSS) 18.0 프로그램을 활용하여 빈도분석과 교차분석을 실시하였다. 결과: 첫째, 자아이미지의 색은 Black (Bk)이 가장 많고 다 음으로 vivid red (R), vivid yellow (Y), vivid yellow red (YR), bright Y, vivid purple blue (PB), white (W) 순이며, tone은 vivid가 가 장 많이 나타났다. 둘째, 자아이미지 그림에 나타난 형태를 분석한 결과, 비구상(32.3\%), 풍경(18.3\%), 사물(17.2\%), 사람(14.5\%), 식물(14.0\%), 동물(3.8\%) 순으로 표현되었다. 셋째, 자아이미지 그림에 나타난 성별차이를 교차분석한 결과, 유채색과 형태에서 유 의한 차이가 나타났고, 남학생은 R계열, PB계열, YR계열, Y계열 순으로, 여학생은 Y계열, R계열, YR계열, red purple (RP)계열, blue (B)계열 순으로 나타났으며, 형태에서 남학생은 비구상, 풍경, 사물, 사람 순으로, 여학생은 비구상, 사물, 식물, 사람 순으로 나 타났다. 결론: 뷰티전공 대학생의 자아이미지 그림은 주로 활동성과 주목성이 강한 색과 비구상적인 형태로 표현되고 있어서, 자신 을 자유롭고 열정적인 이미지로 인지하는 반면 혼란스럽고 불확실한 존재로도 생각하고 있음을 알 수 있다.

핵심어: 자기이미지, 색, 형태, 대학생, 뷰티전공

\section{참고문헌}

김미경. 사례를 통한 색채치료. 학림, 서울, $\mathrm{p} 29,2010 \mathrm{~b}$.

김수정, 권혜진. 자아이미지가 시각이미지 수용에 미치는 연관성 연구: 20 대 여대생을 중심으로. 기초조형학연구, $12: 99-$ 112, 2011.

김애경, 제기연. 미용색채학. 교문사, 파주, $\mathrm{pp} 107-113,2013$.

김은애, 이명희. 가치관과 의복이미지 및 의복디자인 선호도에 관한 연구. 복식, 18: 269-281, 1992.

김재은. 그림에 의한 아동의 심리진단. 교육과학사, 파주, pp103-105, 1998.

김화중. 색채심리. 동국출판사, 파주, p159, 2010a. (파버 비렌. 1950.)

박화순. 성격특성에 따른 색채의 속성별 의복색 선호도. 복식, 26: 87-100, 1995.

성기혁, 우예순. 선호색, 자아 이미지색, 모노톤광고 선호색의 상관관계 연구. 커뮤니케이션디자인학연구, 35: 182-190, 2011.

심정희. 중년 여성의 자기 이미지 유형화에 따른 의복 이미지 평가와 선호. 한국의류학회지, 30: 1608-1617, 2006.

이명희, 김현주. 의복 스타일 이미지 선호와 자기이미지와의 관계 연구. 복식, 33: 41-53, 1997.

주영주, 이순희. 한국 중년 여성의 라이프스타일이 메이크업 추구이미지와 화장품 구매행동에 미치는 영향. 아시안뷰티화장품

학술지, 13: 533-542, 2015.

한국미술심리치료협회. 그림으로 마음읽기: 두 번째 이야기. 한국미술심리치료협회, 부산, p113, 2010. 


\section{中文摘要}

\section{美容专业学生自我形象表达颜色和形态的意义分析}

吳允京 ${ }^{1}$, 金愛卿 $^{2+}$

${ }^{1}$ 昌信大学美容艺术学科, 庆尚南道昌原市, 韩国

${ }^{2}$ 東明大学美容学科, 釜山, 韩国

目的: 探讨美容专业学生自我形象绘画中呈现自我形象的颜色和形态特征, 并分析其视觉化的自我形态的含义。方法: 让 美容专业男女大学生想像自己的形象, 在 120 种颜色组成的调色板中, 选择符合自己形象的3种颜色, 并自由地绘出自 己的形象。数据分析利用Statistical Package for the Social Sciences（SPSS）18.0软件进行频度分析和交叉分析。结果: 首先，在自我形象表现的颜色中，黑色是选择最多的，其次是 vivid red（R）、vivid yellow（Y) ( $Y$ )、vivid yellow red $(Y R)$ 、 bright $Y$ 、 vivid purple blue (PB) 以及white (W) 等 ; 在色调中vivid出现最多。第二, 自我形象人物画的分 析中，依次表现为非客观人物（32.3\%）、风景（18.3\%）、对象（17.2\%）、人物（14.5\%）、植物（14\%）以及动物 （3.8\%）。第三，对自我形象绘画中性别差异的交叉分析表明，男性和女性在色调和形态上存在显著差异。在色调分析 中，男性倾向于使用R、PB、Y和Y系列的颜色，而女性则倾向于使用Y、R、YR、 red purple (RP) 、blue (B) 系列的颜 色。在形态分析中, 男性依次表现为非客观、风景、物体和人，而女性则表现为非客观、物体、植物和人的顺序。结论: 美容专业大学生的自我形象图形主要表现为以活动性和注意力为中心的色彩和非形象形态为主, 并认为自己是一个自由 而热情的形象，是混淆和不确定的。

关键词: 自我形象, 颜色, 形态, 大学生, 美容专业 